\title{
Measuring UK inflation
}

\section{Office for National Statistics}

\section{SUMMARY}

The Office for National Statistics collects a large number of prices every month to produce the retail prices index (RPI). Some perceive that consumer inflation is higher than the official measure. This article looks at the variations in price change for goods and services and the relative proportions consumers spend on them and suggests why some people think inflation is higher.

Households with different levels of income have different spending patterns, and these spending patterns affect each household's experience of inflation. For example, households with the lowest level of income spend a greater proportion on food whereas households with higher income spend more on petrol.
he retail prices index (RPI) is an important measure of inflation. It is used for the indexation of various incomes and prices and the uprating of pensions, benefits and index-linked gilts. Currently, some people perceive that consumer inflation is higher than the official measure; some believe that particular groups of households have higher inflation rates than others.

This article provides a short explanation of the processes involved in calculating the RPI and then examines perceptions of the rate of inflation and the contributions of different goods and services to the headline rates of inflation. It explains which ones are pushing up inflation and which are having a downward impact on the inflation rate. It looks at households' spending patterns and how they vary by income group and household composition.

The article draws on an analysis of individual households' inflation rates to obtain estimates of price inflation for particular household groups. The analysis uses details of 6,000 households from the Office for National Statistics (ONS) Expenditure and Food Survey (EFS). The EFS asks households to complete a twoweek diary of expenditure and collects additional information about major purchases over a longer period (such as furniture over the past three months) and regular payments that are made (such as energy bills). For the analysis, an inflation rate was calculated for each household record from the EFS. The calculation is based on the RPI, rather than the consumer prices index (CPI), as the RPI weights are derived largely from the EFS data on households' expenditure, whereas CPI weights are derived from the National Accounts estimate of household expenditure, which is not available on an individual household basis.

The article comprises six sections, which are outlined below.

How is the rate of inflation calculated and used?

The RPI measures the change in price of a fixed basket of representative goods and services, through the collection of over 120,000 prices every month. The resulting inflation estimates are an average of the change in price for goods and services. It is not an average measure of price changes experienced by each household. This section explains how the RPI is compiled and explains the differences between the RPI and CPI.

\section{Why do people think inflation is} higher than estimates published by ONS?

A common perception is that inflation is higher than the RPI estimates. Perceptions are influenced by many factors including the price of frequently purchased goods and services and media reports. For example, some media reports have been suggesting that the cost of living is higher than the official consumer inflation figures; in particular, they have quoted their own or unofficial cost of living indices. This section explores these issues. 
What is pushing inflation up and pulling it down?

This section of the article shows which goods and services are having the largest upward pressures on the RPI, and which goods and services are having a downward pull.

\section{Household spending patterns}

This section provides an analysis of household spending patterns for some of the goods and services that are having the largest upward and downward effects on the RPI. It shows how the proportion spent on these particular items varies for households of different levels of total expenditure.

Price changes experienced by income group and household type

This part of the article draws on the analysis using data from the EFS to calculate the price change experienced by different income groups and household types.

\section{Conclusions}

This section draws the conclusions of the article.

\section{How is the rate of inflation calculated and used?}

This section gives a brief overview of the processes involved in producing the headline RPI estimate.
How is the RPI calculated?

The RPI and CPI both measure the changing cost of a fixed basket of goods and services, ensuring that the indices capture price changes rather than changes in consumers' expenditure patterns. An explanation of why ONS publishes two estimates of consumer inflation and the main differences between these two measures is provided in Box $\mathbf{1}$.

ONS collects 120,000 separate price quotations every month from randomly selected outlets, including those in shopping centres, out-of-town retail outlets, supermarkets, corner shops and the internet. Price collectors visit shops in 141 locations across the UK to collect over 100,000 prices of around 600 representative goods and services typically bought by UK households. The large number of locations ensures that variations in price change across the UK are captured. For some goods and services, the same price is charged throughout the country, for example, TV licences, newspapers and purchases from catalogues. These prices are collected centrally and account for over 12,000 prices. The large number of prices collected for each item in the sample means that there is a broad representation of brands. For example, over 130 prices are collected for a box of 80 tea bags, including all the main brands as well as supermarkets' own brands.

The items included for price collection are referred to as the basket of goods and services. This basket contains a sample of representative consumer goods and services on which households typically spend their money. The prices of these goods and services are used to give a reliable measure of price movements for a broader range of items. The number of items chosen to represent each product group depends on the expenditure on the group and the variability of price changes. This information comes from the EFS and other sources, such as information from market research.

Households spend more on some items than others, and the amount they spend on an item influences the sensitivity of the index to price changes for that item. For example, a 10 per cent rise in the price of petrol should have a larger impact on the RPI than a 10 per cent rise in the price of tea. To reflect this, products are grouped together, and a weight is allocated to represent the appropriate share of household expenditure. The weights for the RPI are derived mainly from the EFS; this covers UK private households only, and their expenditure in the UK. For more information on the construction of weights, see Baran (2008). It is important to bear in mind that the RPI basket of goods and services represents all goods and services bought by households. As not all people smoke, drink, drive, own their own home,

\section{Box 1}

\section{The two measures of inflation}

\section{Why does the ONS publish two measures of inflation?}

A single measure of inflation would not be able to meet all users' needs.

The RPI is the older and more familiar measure of inflation. It is used for the indexation of various incomes and prices and the uprating of pensions, benefits and index-linked gilts. The RPI provides a consistent series back to 1947, allowing analysis of price change over time. In contrast, the CPI is available back to 1997.

The CPI is the main measure of consumer price inflation for macroeconomic purposes in the UK. It uses methods that are consistent across the European Union, allowing comparisons of the rate of inflation across European countries. It forms the basis for the Government's inflation target that the Bank of England's Monetary Policy Committee is required to achieve.

\section{Key differences between the CPI and RPI}

There are differences in the goods and services represented in the basket:
- the CPI excludes a number of items included in the RPI mainly relating to housing costs, for example council tax, mortgage interest payments and depreciation (major repairs)

- the CPI includes some charges for financial services, for example, stockbrokers' charges, which are excluded from the RPI

The way prices are combined using people's spending patterns are different:

- the CPI represents a broader population than the RPI. The RPI excludes households with the top 4 per cent of income and excludes around 20 per cent of pensioner households - those that derive at least three-quarters of their income from state pension or benefits. All other pensioner households are included

- the CPI produces weights for items in the basket using a breakdown of household expenditure taken from National Accounts. The RPI largely uses the EFS to calculate weights

Different mathematical formulae are used for combining the prices collected for each item in the basket.

For more information on the methodological differences, see ONS $(2003,2007)$. 
and have dependants, by definition the headline rates of inflation will include the price changes of items which are not necessarily bought by every household.

\section{Why do people think inflation is higher than estimates published by ONS?}

The common perception is that inflation is higher than the RPI estimate. Perceptions are influenced by many factors, including the price of frequently purchased goods and services and media reports.

People tend to notice when prices increase: if a price is unchanged or has fallen, it leaves less of an impression. This can lead to the view that prices are increasing even if it only applies to a small number of items. This is particularly the case when the price of goods and services bought regularly and often, such as food and petrol, increase, while the price of items bought infrequently, such as televisions, computers and clothing, decrease. Households notice that the cost of purchasing their weekly shopping has increased but are less inclined to notice that the price of an item bought once every few years has fallen or has stayed the same. Recently, there have been large increases in petrol and food prices but decreases in the price of leisure goods and electrical equipment. The change in the price of clothing is less obvious, as consumers may not purchase directly comparable items at regular intervals.

The media also have an influence: there is a tendency to report increasing prices rather than decreasing prices. Some media reports are suggesting that the cost of living is higher than the official inflation figures, in particular they have quoted their own or unofficial cost of living indices. These indices typically use a small number of items, collecting only a few prices for each item and the brands selected are not necessarily representative of the average price moves for the item. For example, in one index, the price of tea bags was estimated to be rising by 67 per cent, whereas the official data, which is based on 130 price quotes covering 20 different brands, showed a rise of less than 5 per cent.

The RPI measures the average change in prices by calculating the change in price of a fixed basket of goods and services bought by UK households. This is not the same as measuring the individual rate of inflation for each UK household and taking an average. Every household is different, spending different amounts of money on a different basket of goods and services, impacting on the rate of inflation experienced by that particular household. Households which spend relatively more on items with larger increases in prices will have a higher personal inflation rate; those who spend more on items with lower price increases or falls will experience a lower rate of inflation.

An analysis of 6,000 households from the EFS, for the 12 months to April 2008, shows the diversity of expenditure patterns. This analysis suggests that 80 per cent of households experienced average price changes of between 2.7 per cent and 6.1 per cent, and that the price changes experienced by 50 per cent of households were in the range 3.7 to 5.3 per cent. These ranges compare with the estimate for the average of all households (that is, including the top 4 per cent of earners and all pensioners) of 4.5 per cent and the published RPI for April of 4.2 per cent. The ranges for 80 per cent and 50 per cent of households may seem narrower than expected, but it should be noted that the approach used only reflects the variation in the spending pattern of each household. It does not account for price change differentials arising because different household groups purchase items from different regions, from different types of outlets, nor from the purchasing of different brands or types of items. If these other variations could be incorporated into the calculation, there might be greater differences in the individual inflation rates (see section on 'Price changes experienced by income group and household type' and the technical note for an explanation of the methodology used and limitations of the approach).

ONS has produced a personal inflation calculator allowing individuals to calculate their personal inflation rate. The calculator uses the individual's expenditure patterns on the main categories of goods and services in a similar way to the RPI to estimate a personal inflation rate. For an introduction to the personal inflation calculator, see Powell and O'Donoghue (2007). The personal inflation calculator can be accessed on the ONS website.

\section{What is pushing inflation up and pulling it down?}

The discussion of public perceptions of the rate of inflation concluded that they are affected by several different factors, including the rising prices of some frequently purchased goods and services. The following section examines the movements of various groups of goods and services within the RPI.

Variations in the rate of inflation for different goods and services

In the year to July 2008, the RPI rose by 5.0 per cent. This increase takes into account the weight of each component as well as its movement.

The contribution of each division to the RPI growth rate is shown in Figure 1. Food recorded the largest upward contribution to the RPI in July, contributing 1.3 percentage points to the RPI figure for the year to July, the largest contribution from any component. Motoring expenditure, housing, and fuel and light also had large positive impacts. Downward contributions came from clothing and footwear and leisure goods.

The price rises for the key drivers to the RPI (food, housing, petrol and energy) are mostly driven by international rather than

\section{Figure 1}

\section{Contribution to the RPI all items 12-month rate, 12 months ending July 2008}

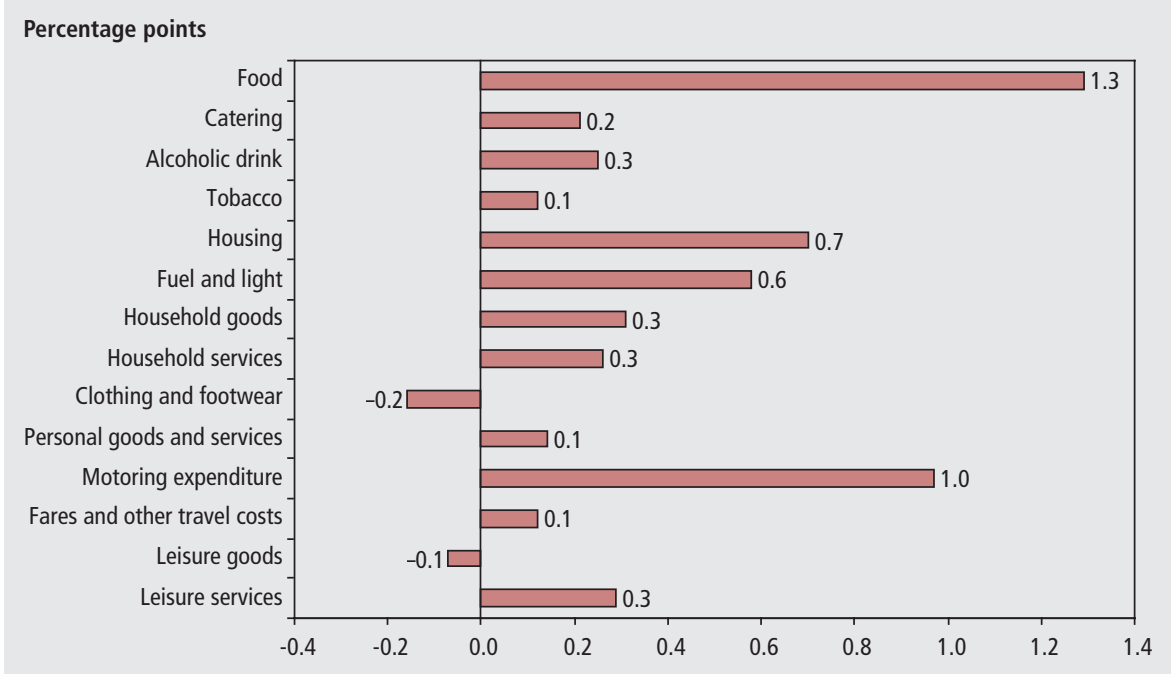


domestic pressures. The price of oil has soared due to global demand and supply pressures, continuously breaking record highs, leading to high fuel prices. Large increases in the price of wholesale gas have impacted on retail gas and electricity prices in the UK. World food prices have risen over the last year as increased demand and poor harvests led to sharp rises in the wholesale price of wheat, soya, rice and corn.

As suggested in the previous section, the components with the largest positive contributions, such as food and petrol, are the goods that people buy on a regular basis. In contrast, those components that are bought on a less regular basis, such as clothing and footwear, have experienced smaller price increases or in some cases price falls. This is likely to have contributed to the public perception that inflation is higher than the official estimates suggest.

The components with the largest positive and negative contributions to the RPI (food and clothing and footwear) can be split down further into subgroups.

The rate of inflation has been increasing since summer 2007 for many sections within the food group. Products such as butter and eggs have experienced large price increases: in the year to July, prices have increased by 37 and 36 per cent, respectively. Other products have also experienced an increase in the rate of price inflation: poultry increased by 24 per cent in the year to July, bread by 20 per cent and cereals by 18 per cent (Figure 2).

Within housing, all components contribute to the upward effect. These include rent, house depreciation (major repairs) council tax/rates and mortgage interest payments.

While some product groups have been experiencing strong positive inflation, others have been recording lower rates of inflation, or even price cuts. Figure 3 shows the components of the clothing group. The price of women's outerwear fell by the greatest amount, recording a fall of 8 per cent in the year to July. Prices also fell for men's outerwear and children's outerwear.

\section{Household spending patterns}

This section provides an analysis of household spending patterns for some of the goods and services that are having the largest upward and downward effects on the RPI. It shows how the proportion spent on these particular items varies according to the level of household expenditure. Housing costs are not included, as expenditure on housing in the RPI is not derived from the EFS.

\section{Figure 2}

\section{Selected RPI food components}

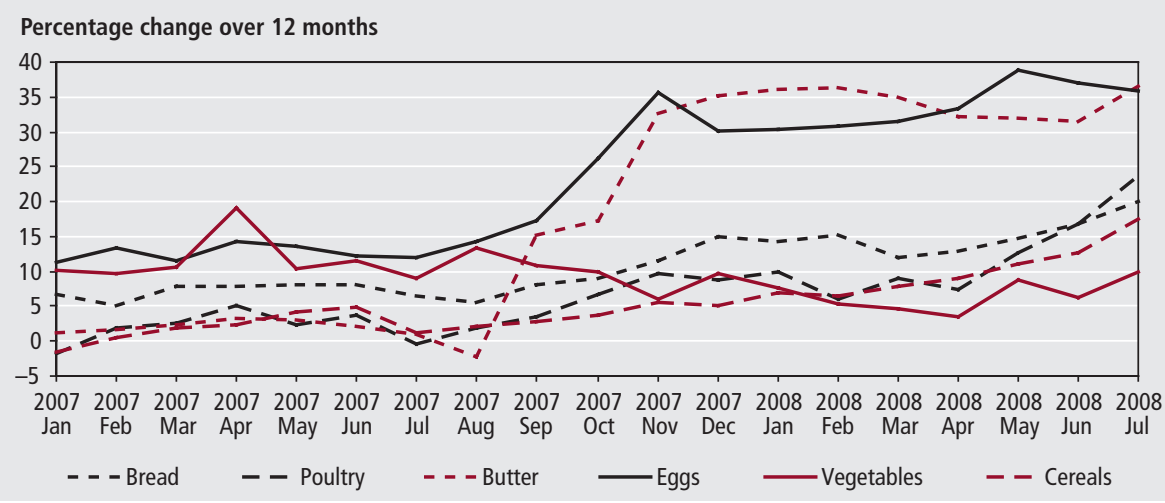

\section{Figure 3}

\section{RPI clothing components}

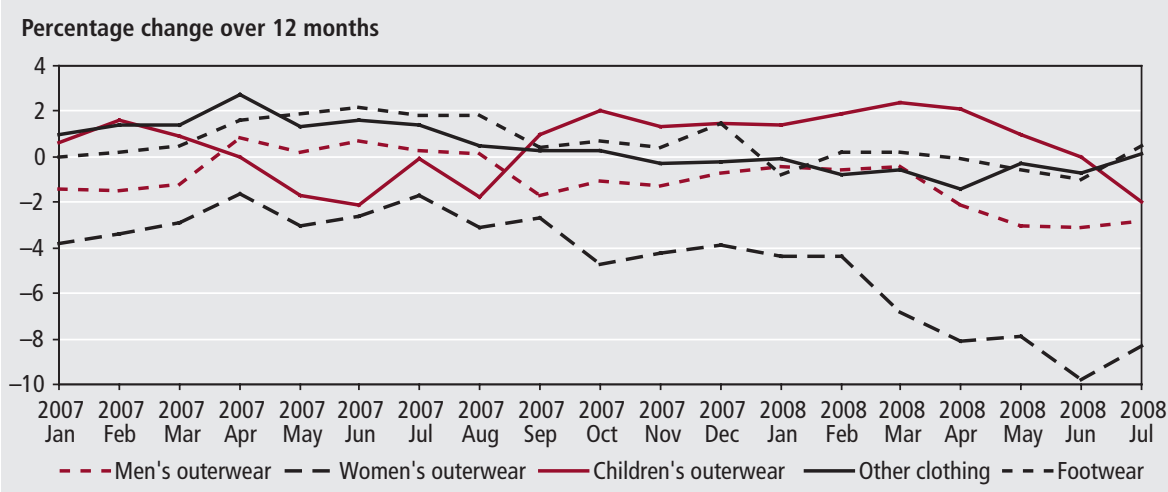

How are household spending patterns used?

Household spending patterns are used to determine the weights of the goods and services that are in the RPI basket. Each item in the basket is given a weight to reflect the proportion of household expenditure spent on the item. For example, an average household spends about ten times as much on sweets and chocolate as it does on postal services; therefore, a 5 per cent increase in the price of sweets and chocolates would have ten times as much effect on the total cost of the basket when compared with a 5 per cent increase in postal charges. The weights are updated at the beginning of each year to ensure that they reflect the latest available information on household spending.

\section{Why are these spending patterns important?}

The spending patterns are important as their key use is to ensure that the price change of each good and service in the RPI basket is allocated the correct weight in the calculation of the RPI headline rate. They also help in determining the content of the RPI basket of goods and services, which is updated annually to ensure that it remains representative of the goods and services which households actually buy.

They are also important to individual households. Every household is different and spends money on different goods and services, and this expenditure pattern is a key determinant of the inflation rate experienced by individual households. For example, take households which spend a large proportion of their total expenditure on items that are significantly increasing in price. These households are likely to experience a higher inflation rate than those which spend relatively more on items which have lower price increases, or are even decreasing in price.

\section{Analyses of household spending patterns}

The EFS is the key data source used in the calculation of the RPI weights. The data used to calculate the 2008 RPI weights have been used to analyse how the spending patterns of different types of household groups vary. Using households' average weekly expenditure, the households have been grouped into:

- top decile: the top 10 per cent

- upper quartile: the top 25 per cent

- lower quartile: the bottom 25 per cent

- bottom decile: the bottom 10 per cent 
The analyses have studied the average weekly expenditure of the household groupings on a particular good or service as a percentage of the total average weekly expenditure of the household grouping.

The goods and services that have been analysed are:

- food, fuel and light, and petrol: these items have recently been significant contributors to the upward pressure to the RPI headline rate

- clothing and footwear: these products have recently been a significant contributor to the downward pressure to the RPI headline rate

- telecommunications and 'furniture, furnishing and electrical appliances': these products have not recently been significant contributors to the RPI headline rate; nevertheless they have attracted media and public interest

Figure 4 shows the proportion spent on each of these goods and services by each of the expenditure groups listed above.

\section{Results}

It can be seen from Figure 4 that the households which have the lowest level of total expenditure spend the highest proportion of their expenditure on food and fuel and light whereas those with the highest expenditure spend the lowest proportion on food and fuel and light. This means that the recent price increases for these products will have had a greater impact on the households which have the lowest level of total expenditure. However, the recent increases in petrol prices will have had a smaller impact on those with the lowest total expenditure, but broadly similar effects for others.

Households which have the highest level of total expenditure spend a higher proportion of this expenditure on clothing and footwear than those which have the lower level of total expenditure. This means that the recent price decreases for these products will have had a more significant impact on the households which have the highest level of total expenditure.

The households with a high level of total expenditure spend a far higher proportion of this on furniture, furnishings and electrical appliances than those with lower total expenditure. The opposite is true, though, for telecommunications, where the households with the lowest total expenditure spend a higher proportion of that expenditure than those households which have a higher level of total expenditure.

\section{Price changes experienced by income group and household type}

Many commentators have suggested that different types of households experience different inflation rates.

This section describes the results of a study of the price changes experienced by households with different incomes and types of household composition over the 12 months to April 2008.

\section{Figure 4}

\section{Average household weekly spend on item as a percentage of total average weekly spend}

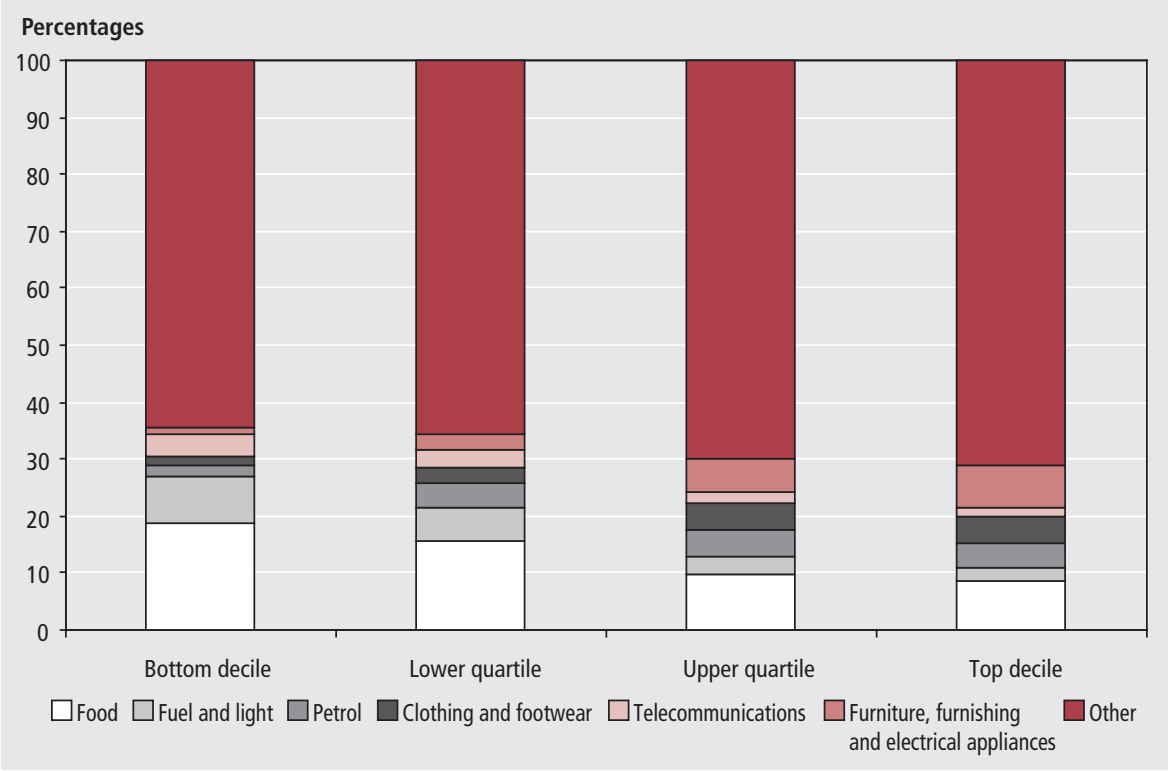

Measuring price changes experienced by different household groups

The RPI gives the rate of inflation for all households. For this article, the EFS has been used to estimate price inflation for particular household groups. These price estimates give an indication of the rate of inflation experienced by each group.

The method used to produce the price inflation rates is comparable with that used in the personal inflation calculator. The 2006/07 EFS contains expenditure data for 6,000 UK households. The spending pattern of each of these households was used to create 6,000 different sets of weights. Each of these was used within a calculation similar to the RPI to arrive at an estimate of each household's expenditure in April 2007 and April 2008. The price change was then determined over the 12 months for each individual household. The individual households were then grouped together for analysing the average rates of, and contributions to, price inflation.

This approach calculates the average change in expenditure using a 'democratic' price measure, where each household is given an equal weight irrespective of expenditure. The CPI and RPI use a 'plutocratic' price index which measures the change in average expenditure, effectively giving households with greater expenditure a greater weight. Rates of price inflation are shown for income deciles and household composition.

For a more detailed description of the methodology, see the technical note.

\section{Households grouped by income} When the households were grouped by income deciles, there was little variation in the average price change experienced by different income groups. From Table 1 it can be seen that the average price change experienced ranges from 4.3 to 4.6 per cent in the 12 months to April. However, as explained earlier, the approach used only reflects the variation in the spending pattern of each household. It does not account for price change differentials arising because different household groups purchase items from different regions, from different types of outlets, nor from the purchasing of different brands or types of items. If these other variations could be incorporated into the calculation, there might be greater differences between the inflation rates of these household groups.

Although different income groups experience different inflation rates, the results from this analysis by household income show less variation in the overall 
Table 1

\section{Estimates of average price changes experienced by households grouped by income decile, 12 months ending April 2008}

\begin{tabular}{lc}
\hline Income decile & Average price change experienced (\%) \\
\hline 1st (lowest) & 4.5 \\
2nd & 4.6 \\
3rd & 4.5 \\
4th & 4.5 \\
5th & 4.4 \\
6th & 4.4 \\
7th & 4.5 \\
8th & 4.4 \\
9th & 4.3 \\
10th (highest) & 4.4 \\
All households & 4.5 \\
\hline
\end{tabular}

\section{Figure 5}

Contribution to price change experienced for certain income deciles, 12 months ending April 2008'

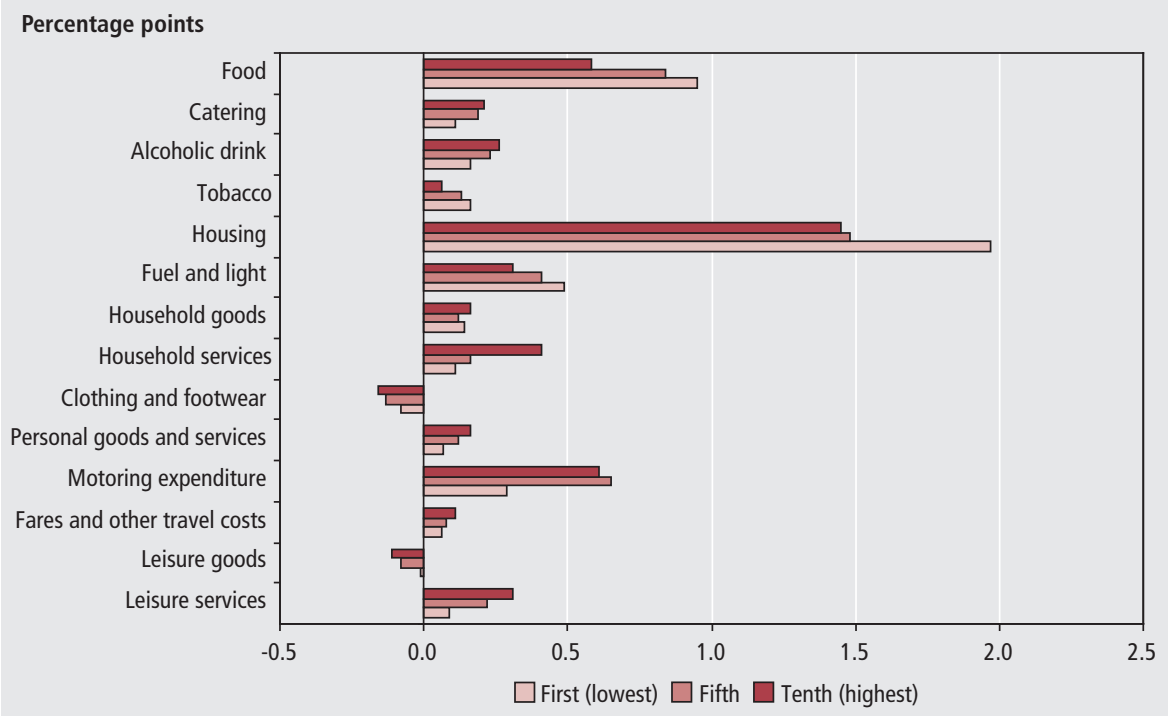

Note:

1 Percentage change for each decile: tenth decile 4.4 per cent, fifth decile 4.4 per cent, first decile 4.5 per cent

price change experienced by different household groups than might be expected. The results do show differences in the extent to which particular goods and services contribute to the inflation rate for households in different household income groups, but these are largely offsetting. Figure 5 shows the percentage points contribution to price change experienced for the lowest (first), near-middle (fifth) and highest (tenth) decile. Comparing the lowest and near-middle income groups, housing costs made a greater contribution to the inflation rate of the lowest group, but this is largely offset by motoring expenditure which made a greater contribution to the inflation rate of the near-middle group. Comparing the highest and near-middle income groups, household services (including fees and subscriptions) make a greater contribution to the highest group, but this is largely offset by food, which makes a greater contribution to the inflation rate of the near-middle group.

Comparing the three income groups together, it can be seen that housing had the greatest impact on the lowest income group. Food had a higher contribution for the lowest and near-middle income groups than the highest group. For the highest income group, a greater contribution came from motoring expenditure than from food. Fuel and light had a positive impact on the price change for all income deciles; the impact was greatest for the lowest income group. The largest positive impact from leisure services (including holidays) and household services (including fees and subscriptions) was for the highest income decile. Clothing and footwear and leisure goods had a negative contribution to the price change for all income deciles, offsetting a small part of the positive contributions. This negative contribution was smallest for the lowest income group.

The results of the analysis conform to expectations as the items that make up the largest part of a household's expenditure are likely to have the largest influence on the price change they experience. If lower income households spend relatively more of their income on necessities such as housing and food, then it would be expected that these components make a greater contribution to the price change they experience than to higher income households. Conversely, higher income households are likely to spend relatively more on luxuries such as leisure goods and services, so that these items contribute more to the price change they experience.

Households grouped by composition Table 2 shows the average price change of households grouped by household composition for the 12 months to April 2008. Households comprising two adults and two children experienced the lowest average household price change of 4.3 per cent. Pensioner households relying on income from state pension or benefits for 75 per cent of their income had the highest household percentage change, 5.1 per cent. Again it must be stressed that the approach used only reflects the variation in the spending pattern of each household. It does not account for price change differentials arising because different household groups purchase items from different regions, from different types of outlets, nor from the purchasing of different brands or types of items.

From the contribution of each household group (Figure 6) it can be seen that single households experienced a larger contribution from housing costs than any other type. However, single-person households experienced the lowest contribution of all types from motoring expenditure. Pensioners reliant on state pension and benefits experienced a larger contribution than any other type for food and 'fuel and light'.

\section{Conclusions}

The CPI and RPI measure the average change in prices by calculating the change in price of a fixed basket of goods and services representing the items bought by all UK households. Importantly, this measure is not the same as the average of all individual inflation rates experienced by all households in the UK.

Every household has a different expenditure pattern, spending varying amounts of money on different items. 
Table 2

\section{Estimates of average price change experienced by households grouped by household composition, 12 months ending April 2008}

\begin{tabular}{lc}
\hline Household composition & Average price change experienced (\%) \\
\hline Two adults, two children & 4.3 \\
Two adults, no children & 4.5 \\
Singles & 4.6 \\
Pensioner, 75 per cent of income from state pensions or benefits & 5.1 \\
Retired/unoccupied and of minimum NI pension age ${ }^{1}$ & 4.7 \\
All households & 4.5 \\
\hline
\end{tabular}

Note:

1 Includes those $20 \%$ of pensioner households where $75 \%$ of income is from state pension or benefits.

\section{Figure 6 \\ Contribution to price change experienced by households grouped by composition, 12 months ending April 2008}

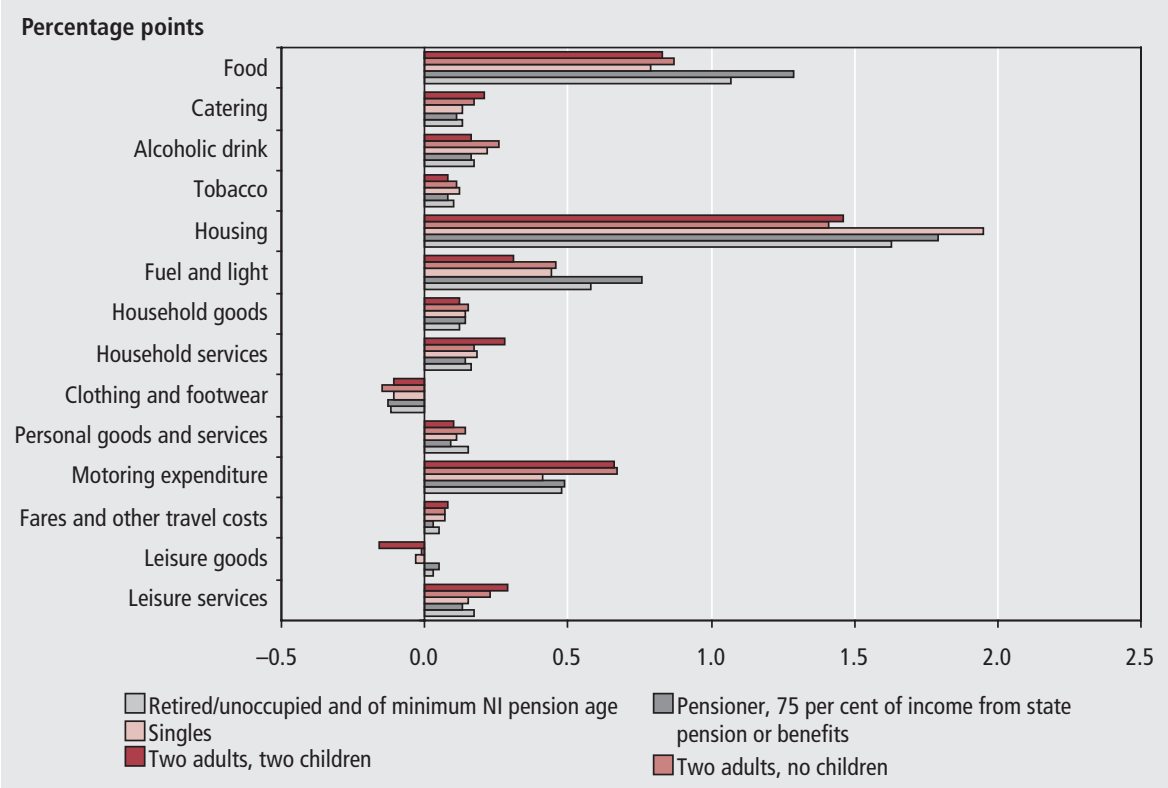

Therefore, every household will experience a different rate of inflation. Households which spend a larger proportion of their total expenditure on items experiencing the largest price increases over the past year, such as food and fuel, would be expected to have a higher individual rate of inflation than those spending a higher proportion of their expenditure on clothing and electrical equipment, which have seen small price increases or price decreases.

Households with the lowest level of total expenditure spend a higher proportion on food and 'fuel and light' than those with the highest level of total expenditure. Conversely, households with the highest level of expenditure spend a relatively higher proportion on items such as petrol and 'clothing and footwear'. This suggests that rising food and energy prices will have a greater influence over the personal inflation rate of households with the lowest level of expenditure.

Analyses using EFS data and a process similar to that used to produce the RPI other variations could be incorporated into the calculation, there might be greater differences between the inflation rates of these household groups.

Analysis by household composition shows that, for the 12 months to April 2008, households comprising two adults and two children experienced the lowest average household price change of 4.3 per cent. Pensioner households relying on state pensions or benefits for 75 per cent of their income had the highest household percentage change, 5.1 per cent. Again, it must be stressed that the approach used only reflects the variation in the spending pattern of each household. It does not account for price change differentials arising because different household groups purchase items from different regions, from different types of outlets, nor from the purchasing of different brands or types of items.

Single households experienced a larger contribution from housing costs than any other group. However, single-person households experienced the lowest contribution of all types from motoring expenditure. Pensioners reliant on state pension and benefits had the largest contribution from food and 'fuel and light'.

\section{CONTACT}

国elmr@ons.gsi.gov.uk

\section{REFERENCES}

Baran D (2008) 'Consumer Prices Index and Retail Prices Index: Updating Weights for 2008', Office for National Statistics at www.statistics.gov.uk/cci/article. asp? id =1991

Office for National Statistics (2003) 'The new inflation target: the statistical perspective' at www.statistics.gov.uk/statbase/product. asp?vInk=10913

Office for National Statistics (2007) 'Consumer Price Indices Technical Manual 2007' at

www.statistics.gov.uk/statbase/product. asp?vlnk=2328

Personal Inflation Calculator at www.statistics.gov.uk/pic

Powell M and O'Donoghue J (2007) 'The personal inflation calculator' Economic \& Labour Market Review 1(1), pp 27-32 and at www.statistics.gov.uk/cci/article. asp? $\mathrm{id}=1707$ 


\section{TECHNICAL NOTE}

Method for producing estimates of consumer inflation for particular household groups

ONS used expenditure data for 6,000 households from the EFS to obtain estimates of price inflation for particular household groups. This technical note explains the approach adopted.

The estimates give an indication of the rate of inflation experienced by each group, but they are not precise. The method used only reflects the variation in the spending pattern of each household, and there are other limitations, as explained in this note.

The process adopted for each individual household was:

- assign expenditure (from 2006/07 EFS) to each of the 85 'RPI Sections' - a classification that breaks each household's expenditure into 85 mutually exclusive and exhaustive groups

- obtain average house prices for each Government Office Region (GOR) from Land Registry offices (and then apply the UK average depreciation rate to obtain average depreciation expenditure for each GOR) and assign this average expenditure if the household owns (or is purchasing) a dwelling (depreciation is applied to RPI on a national basis - this approach takes account of the variation in regional house prices but does not take account of other factors such as the size of the household's dwelling)

- adjust expenditure for known under-reporting using the same process as for the RPI (for example, expenditure on alcohol tends to be under-reported)

- by using RPI price changes at the RPI Section level for all Sections except mortgage interest payments, council tax and depreciation, separately revalue expenditure for each of the 85 Sections in terms of prices from January 2008 (this process is used to calibrate the breakdown with the RPI)

- for any given period (in this case April 2008), separately revalue each Section level expenditure in terms of prices for the period of interest (April 2008), and the same period 12 months earlier (here, April 2007)

- for each individual household, add the section level expenditure to arrive at the total expenditure in April 2008, and the total expenditure in April 2007. Determine for each household the price change over the 12 months (ignoring sources of variability from different outlets, regions and detailed item choices)

- for any particular group of households, determine the average of the rates of price change (this is a 'democratic' measure)

Following such a process produces a useful measure illustrating the different price changes experienced by different types of households (and as such, it is very similar to the broad level approach utilised by the personal inflation calculator on the ONS website). In using such measures, it is important to note the following:

- these measures are produced across all households covered by the EFS and, as such, the scope is wider than that of the RPI which excludes:

- pensioner households which derive at least three-quarters of their total income from basic state pension and benefits, and

- high-income households, defined as those households whose total household income lies within the top 4 per cent of all households

- these measures fail to account for different sources of price variation that individual households may face. This method does not take account of any regional variation in the change in price of the goods and services, nor does it reflect the fact that individuals may purchase one particular brand of a good or service and the price movement for that particular brand will differ from the average price movement for the particular item. Any variation due to different types of outlets is also ignored. For example, the level of detail used in this process has an RPI Section 'Purchase of motor vehicles'; this process does not allow for variation in pricechange experiences arising because different household groups buy different types of cars, or purchase from different types of dealers, and instead applies the average price change for the purchase of motor vehicles to all household types

- the expenditure data for each sampled household is determined from a two-week window, with some supplementation from a questionnaire to capture regular payments such as energy bills and large, less regular, purchases such as furniture

- the process differs from the RPI itself as it does not allow for annual updating of expenditure, nor annual changes to the basket of goods and services - that is, where the RPI is annually chain-linked to account for evolving consumption patterns, this measure assumes fixed expenditure

- the RPI itself is measuring change in average expenditure (a plutocratic measure) and not average change in expenditure (a democratic measure), as calculated here 